\title{
The Importance of Search as Intertextual Practice for Undergraduate Research
}

\section{Brett B. Bodemer}

\begin{abstract}
By first reassessing the role of search in the literacy event of the lower division undergraduate paper, this article argues that searching is not a lower-order mental activity but a concurrent, integral component of the research-writing process. This conclusion has large implications for information literacy instructional design, and several practical applications to further support undergraduate research-writing are outlined.
\end{abstract}

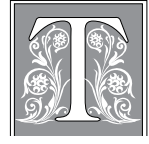

his exploration of information literacy instructional design links theoretical and practical concerns. The ideas articulated here emerged from reflections on instructional sessions delivered to lower-division English and Communications classes in 2009-2010 at the California Polytechnic State University at San Luis Obispo, sessions timed to coincide with the assignment of a research-driven paper. In what follows, I will argue that searching is an integral, concurrent component of a situated whole and is not the strictly lower-order mental activity it is often made out to be. It is an important part of the literacy practice of writing an undergraduate paper. Consequently, from the standpoint of instruction, in an academic environment where subscribed online databases are available, students should be briefly grounded in key database concepts, shown a few essential tricks, then launched into search as soon as possible, engaging them immediately in this variety of intertextual processing that further augments the intellectual development gained through writing a research paper. Additional support for the growth of undergraduate research skills can build on this foundation.

\section{Search and the Undergraduate Paper}

One of the key features of the instructional sessions that generated these considerations was the requirement that students write a paper. This might seem like a minor detail for instructional design, requiring little more than identification of the subject area and a few particulars of the writing assignment. However, strategic instructional design requires a deeper view of the factors at play in the "mere" writing of a paper. Such a view must account for the interests and practices the respective parties bring to the room, conceptions of the relation between research and writing, the role of search

Brett B. Bodemer is Humanities and Social Sciences Librarian and Head of Reference and General Education Instruction in Kennedy Library at California Polytechnic State University, San Luis Obispo; e-mail: bbodemer@calpoly.edu. (C) 2012 Brett B. Bodemer Attribution-NonCommercial (http://creativecommons. org/licenses/by-nc-sa/3.0/) CC BY-NC 
within that matrix, and perceptions of the ultimate value of writing a paper.

One way to envision the broader dynamic of the undergraduate paper is to see it as a literacy event that engages students in a literacy practice. According to David Barton, in Literacy: An Introduction to the Ecology of Written Language, literacy practices are "common patterns in using reading and writing in a particular situation." ${ }^{1}$ A literacy event, on the other hand, is not necessarily a shared and common pattern, but "any activity which involves the written word" and that, in educational contexts, often serves "the explicit purpose of learning." ${ }^{2}$ In the framework of our sessions, both the librarian and faculty are well versed in the patterns common to the literacy practice of writing papers, but the students much less so. Enter, then, the "literacy event" of the paper, a ritualized activity through which students enter into the literacy practice of writing papers. In the grand scheme of things, the papers are not viewed as ends in themselves (as if faculty were somehow short of reading matter) but rather for the ultimate values of enhanced written communication and critical thinking skills nurtured through the totality of the activity. ${ }^{3}$

In strategically designing the libraryrelated component of such a literacy event, it is crucial to consider the coincidence and divergence of interests, cultural knowing, and current literacy practices brought respectively to the session by faculty and students. ${ }^{4}$ Faculty are steeped in a tradition of literacy practice reliant on credible sources and the conscientious habit of creating clear and proper trails of citations. In my experience, faculty often say they are bringing the students to the session so they can find good sources and learn how to cite properly. But there are more oblique-and usually unexpressed-learning objectives. First, while faculty may say that they want students to find good, scholarly sources for their papers, what they ultimately want is for students to learn how to find such sources.
Moreover, though never put in such broad terms, they also want students to exclude sources.

This last goal often finds expression as the faculty lament bewailing indiscriminate student use of Internet sources. Whether or not student use of Web sources is as indiscriminate as most faculty might think, ${ }^{5}$ students do bring their own literacy practices to these instructional sessions. Undergraduates, unlike faculty, are not "expert researchers" steeped in a tradition of relying on library resources for informing their written work. ${ }^{6}$ College students rely extensively on Internet search engines for information and frequently glean information from Web sites, including Wikipedia. ${ }^{7}$ Moreover, student information gathering and writing practices are formed before reaching college age. ${ }^{8}$

Strategic design of the session also requires consideration of what importance(s) students place on the research paper. In their 2010 iteration of How College Students Evaluate and Use Information in the Digital Age, Alison Head and Michael Eisenberg reported that 97 percent of students engaged in a course-related research paper viewed the importances of this task as finishing the paper and getting a good grade..$^{9}$ This is no grounds for astonishment, but, interestingly, a majority of students acknowledged other measures of importance. More than three quarters (78\%) also felt that it was important to conduct comprehensive research on a topic and to learn something new. ${ }^{10}$ It was encouraging to learn that 64 percent indicated improving research skills and writing skills was also important. ${ }^{11}$ By these last measures of importance, faculty and student interests in the "writing of the paper" are more closely aligned, and good instructional design of the library component for the literacy event of the undergraduate paper should nourish the genuine desire of those students interested in improving research and writing skills.

It is also important to conceptualize 
the relation of the research process to the writing process. While the research process might be viewed as subordinate to the writing process, and writing can be viewed as subsequent to the research process, ${ }^{12}$ the two processes can also be conceived of as fully integrated. ${ }^{13} \mathrm{I}$ am inclined to the latter view and, for confirmation, simply ask readers to interrogate their own practice. For myself, I never select a topic, research it, and then write about it in single sequential order. Rather, I grope my way to a topic through initial curiosity and preliminary research forays, then refine it via ongoing research and drafts. The research-writing process is dynamic, and students attending the sessions should be encouraged to conceptualize and experience research not as a "do-it-once-and-done" deal, but as an ongoing process that informs and shapes what finally emerges as the finished paper.

The research-writing cycle mirrors the interior dynamic of searching, which itself can be viewed as a series of epicycles. Although librarians and information scientists often schematize the fulfillment of information needs as sequential to isolate the key components, such compartmentalization inadvertently obscures the recursive, concurrent, and iterative nature of the processes involved. ${ }^{14} \mathrm{Al}$ though several such schema have been devised worldwide, the most prevalent framework in North America, and also influential in some European countries, has been provided by the Association of College and Research Libraries (ACRL) in the form of the Information Literacy Competency Standards for Higher Education. ${ }^{15}$ The ACRL Standards portray the fulfillment of information needs by describing exactly what an informationliterate student should be able to do. According to the five ACRL Standards, the information-literate student: 1) "determines the nature and extent of the information needed"; 2) "accesses needed information effectively and efficiently"; 3) "evaluates information and its sources critically and incorporates selected information into his or her knowledge base and value system"; 4) "individually or as a member of a group, uses information effectively to accomplish a specific purpose"; and 5) "understands many of the economic, legal, and social issues surrounding the use of information and accesses and uses information ethically and legally."16

The ordering of the first four Standards suggests a temporal sequence that is simpler than the reality of research-writing. If one imagines these intellectual operations unfolding in real time, it is easy to see how such delineations begin to fail. Determining "the extent of information needed," accessing "the needed information," evaluating "information and its sources critically," and using "information effectively" are not discrete and sequential, but cyclical, often simultaneous, and mutually influencing. ${ }^{17}$ For recent statistical support of just one aspect of this dynamism, one can point to Head and Eisenberg, who report that two-thirds of their respondents did not view the evaluation as a "separate, disembodied step in their research process."18 The delineations of the ACRL Standards, although useful for instructional design and assessment, inadvertently instantiate false dichotomies in the conceptualization of the researchwriting process. For example, "use" of information is postulated as separate from "evaluation" of information. This ignores the fact that in winnowing results/sources from consideration for further use, one is both evaluating information and using it via evaluation-even if just to relegate it to the discard pile. The desires, decisions, evaluations, and further pursuit of information required while researchingwriting a paper are not in practice so easily divorced from each other.

The key commonality between the activities of search (taken as the process of finding what one will read at more length), research (taken as carefully reading what one has found), and writing (integrating what one has chosen to read 
at length into a new, unique text) is their mutual and reciprocal status in a single dynamic fabric of intertextual practice. All three activities contribute to increasing skills in intertextual practice, which in turn fosters enhanced communication and critical thinking skills. ${ }^{19}$ Few will argue with the idea that research and writing make a contribution to the development of these latter skills. ${ }^{20}$ But some may balk at the suggestion that searching itself may do so. In the hierarchy of information literacy skills, search is typically assigned a low place on the totem pole. Even so recent a publication as the article by Head and Eisenberg relegates search to the level of lower order thinking. In doing so, these authors follow the ACRL Standards' traditional application of Bloom's learning taxonomy, associating lower-order thinking skills with "devising and using an effective search strategy" and reserving higher-order skills for activities "such as synthesizing information to create new concepts." ${ }^{21}$

To understand how searching constitutes practice in, and development of, intertextual skill, it is helpful to consider research discussed by Jean-François Rouet in The Skills of Document Use: From Text Comprehension to Web-Based Learning. Rouet explores the act of searching within single documents, with the use of text markers such as headings, but also investigates information searches across multiple documents, in addition to the searching of complex documents such as Web sites. Whether conducted in one document or across several, Rouet sees information search as ultimately governed by "goal representation and the ability to determine if that representation has been satisfied." 22 Rouet explores a range of concurrent processes, including "assessing the relevance of information categories, making decisions, and holding intermediate information in mind while pursuing the search." ${ }^{23}$

According to Rouet, "document search relies on specific cognitive processes and strategies, quite distinct from those used when reading for comprehension or memory. Answering questions from texts requires one to make extensive use of text organizers in order to proceed quickly to the relevant passage." ${ }^{24}$ However, "search and comprehension may interact, as searching a document influences the reader's representation of the document's contents. Executive control processes play a critical role in planning and conducting efficient document search." 25

Moving to multiple document search, Rouet stresses document integration, and singles out the salient importance of handling source information. He writes:

\section{Reading multiple documents re- quires readers to identify the ori- gin of each document, to compare information across documents, and to integrate information into a coherent representation. These operations put a strong emphasis on the identification and use of source information. ${ }^{26}$}

Rouet also addresses the searching of complex documents. He defines complex documents as "artifacts that include more than one piece of coherent, continuous text"; as examples, he cites "a textbook page, a scientific report, a technical manual, or a Web site." 27 If we consider this definition in the light of the students in our instructional sessions, we realize that they are searching multiple documents (articles, result lists, abstracts, citations, subject terms, and even keywords) within the setting of a highly dynamic complex document: namely, a database.

What confronts us in database searching is a set of complex relationships between pieces of text (or, as Rouet puts it, "specific information pieces"). ${ }^{28}$ The crucial pieces serve individually and collectively to signify further content that lies beyond. It is a world not wholly unknown to students, for, if they come to database searching from a grounding in Google searching, they are familiar with a process that retrieves results in 
which their original keywords appear embedded and bolded in small strings of text. The keyword-triggered strings, and even the URLs, directly and indirectly represent content. These are "information pieces" upon which the searcher makes an estimation of whether or not it is worth clicking to see the item whose full content is thus minimally represented in the result.

Databases provide a wider range of the relationships and directional paths between "information pieces" than Google search-results. Page layout, fonts, and a host of text markers in these complex documents create an environment in which one can scan and move from para-text to full text in a variety of ways. Abstracts, subject headings, keywords, and parts of citations all point to items beyond themselves in different ways. The variety of interrelated "specific information pieces" have multiple relationships to other "specific information pieces," and successful navigation of the pieces brings one rapidly to longer texts that provide (if all goes well) the kind of information desired.

It should be added that such textual tools are by no means unique to the current technological environment. In the European medieval shift from monastic to scholastic learning, texts were outfitted with divisions into books, chapters, and paragraphs and were equipped with running titles, analytical tables of contents, indexes and footnotes, all of which made them easier to search..$^{29}$ In fact, use of tools that facilitate consultation rather than strict linear reading may constitute a critical part of scholarly activity: as no one has time to read everything, the use of such tools is necessary to scholarship.

Searching for information in such a way, then, is by no means a simple intellectual operation. As Rouet writes:

Remembering a search objective ... requires an active effort to hold in mind information while being permanently challenged by incom- ing new information. Information search also requires readers to evaluate incoming information sources properly. This aspect of search is closely related to the "sourcing" heuristic in document integration. A source has to be both relevant and credible. These qualities may be established by looking at specific information pieces. But this is done only when the searcher engages in active, strategic reading. ${ }^{30}$

Practice in searching, then, engages students in intertextual skills in the larger framework of the undergraduate paper. It involves complicated acts of evaluation and decision making. Students who learn to read and navigate the multiple points of content representation in databases are engaged in grappling with the structure of texts and the organization of knowledge at large. Though the work they do at this level remains largely unseen, it is no less important for all that. A professor or instructor may never see all the sources that were rejected, nor all the scanning, guessing, and decisions that went into the winnowing, nor all the changes of tack the paper may have taken as a result of searching. The quality of the paper, for a student with little skill in writing papers, in fact may reflect very little of the mental effort and strain that went into its writing. Yet such effort and strain are integral parts of the totalizing literacy event of the undergraduate paper.

\section{Implications for Instruction}

So how might the foregoing considerations serve to shape instructional practice? Not only for the one-shot session immediately supporting the lower-division research paper, but also for further work with undergraduate researchers, both in and out of the classroom setting?

First, an accounting of the various differentials between student and faculty knowledge and literacy practices can inform multiple aspects of effective instructional design. It is imperative to 
acknowledge that the prevalent student literacy practice of Internet searching shapes students' conceptions of search, information organization, and of information sources. It isn't simply that faculty know more facts about a subject than students do; faculty also know far more about the available range and types of information sources. ${ }^{31}$ A parallel gap exists with respect to research terminology. While, to faculty, the stock-in-trade terms of research-abstract, index, thesaurus, peer-reviewed, subject-heading, and the like-are mental wallpaper, such terms are scarcely known, if at all, to students. In the context of a single session in support of the research paper, there is no hope of filling all these gaps at once. What it can offer is a good start. Students do not need an hour-long barrage of terms, definitions, and frenzied online screen-hopping. Rather, what is needed is a minimalist salvo conveying essential concepts, one that blends strategic language with calculated screen moves that consciously build on current student literacy practices.

For the same reason, database and OPAC (Online Public Access Catalog) search demonstrations should strategically proceed from a base of what students know. In the early part of the 21st century, this means starting with keyword searching as most often practiced on Internet search engines. ${ }^{32}$ Though this may seem most un-librarian-like, a broad keyword search starts students with what is familiar to them-and not only is this effective pedagogically, but it is also the first move in a recognized and effective database search strategy. ${ }^{33}$ Although students basically trust Google to "understand" a search, ${ }^{34}$ it is best to raise student awareness of how keyword searching operates in the Google environment, including a brief discussion of some of the chief factors influencing the ordering of a result list. It is also important to initiate a conversation that makes students aware of the fact that they are already making guesses when they select items from a result list. Moving from a Google framework, keyword searching can then be deployed in a database environment. The demonstration can strategically shift to show the differences and gains obtainable by making use of subject headings, fielded searches, thesauri, and indices. This is a way of taking students from what they currently do and know (somewhat) to something new that they can begin to do and know for themselves. Such a demonstration should avoid long enumerations of sources and terms, but rather, work a limited number of sources and terms into the natural flow, with minimal explanation, trusting that such "signposts" will make more sense as the students begin engaging in practice.

Such minimalist presentations and demonstrations should be geared to getting the students into the practice of searching as quickly as possible. It is not talk about something that will increase their skills. Rather, it is direct engagement in the practice itself that will develop their intertextual skills. Of course, according to this logic, it might be argued that all introduction should be dispensed with and that students should be launched directly into searching. However, Rouet notes that searchers should have some ability to reason about the varieties of content representation, ${ }^{35}$ and the minimalist foregrounding should give them "just enough" to begin engaging in the practice itself.

In ideal circumstances, instruction ranges beyond a single session, and some faculty are willing to dedicate an extra class period to the more specifically "search" component of the research paper. In this case, according to the arguments presented here, second sessions should employ a framework in which the students actively search for sources, engaging the OPAC and databases, while the librarian roams among the searching students, answering specific questions when various roadblocks appear, crouching down or sitting next to the students, clarifying something here, explaining 
something there. Moving away both from generalities and a hierarchically superior position as the focal point of the classroom setting, the instructional provider now continues interventions in the role of a coach or counselor. ${ }^{36}$

If opportunities arise for multiple sessions with a single cohort of students, similar strategies can be deployed in a deliberately scaffolded progression. For instance, in an inaugural session, keyword searching can be used to introduce OPAC searching, shifting to subject and fielded searches. If the session is held in the library, immediate practice can be linked to treasure hunt activities by means of which the purposes and relations of the various information pieces in the OPAC can be made concrete through direct experience. For instance, the effect of collocation through subject headings makes more impact when one discovers that topically related items live in the same neighborhood on the shelves, and students are better able to understand that even the first parts of a call number indicate something about an item's contents. Furthermore, the various items brought back from the treasure hunt can be used to open a discussion about the differences between types of sources. Such a discussion, solidified by the look and feel of tangible magazines and scholarly journals, lays the foundation for an ensuing session devoted to database searching. Because databases bear undeniable traces of their ancestry in print publication traditions, ${ }^{37}$ the physical exemplars of journals and magazines can serve as vivid templates to explain the contents of databases and the relation of contents to functions. After such a brief conceptual introduction, the majority of the second session can be devoted to hands-on database searching for sources related to the immediate paper or assignment. A third session in this sequence can focus on the realm students already know, Internet searching, but prefaced with a collaborative exercise on evaluation. An excellent exercise for this is the low-tech but engaging Reliability-
Spectrum exercise.$^{38}$ At the start of the session, a double-arrowed line is drawn on a board tagged as "more reliable" at one end and "less reliable" on the other. The instructor roams among the students and hands out large sticky-notes with chunks of information such as "peer-reviewed" or ".gov" or "cool graphics" and the students place their sticky-notes on what they deem to be the appropriate part of the spectrum. During the bulk of the session, students explore designated sites as teams, then vote on the reliability of each site, giving reasons for their votes. At the end of the session, the class as a whole then decides which sticky-notes should be moved from their original positions on the reliability spectrum. This not only acquaints students with the factors they should consider in evaluating sources, and the need to balance multiple factors, but it also alerts them to the fact that they are already "guessing" and that a more fruitful approach is to deliberately engage in the practice of a more "educated" guessing. ${ }^{39}$

Moving from support for lowerdivision courses to more advanced papers, there are further opportunities for librarians to reinforce the intertwining of search skills with research and writing skills. Just as the writing skills should move to a more complex level, student awareness and use of sources should be encouraged to do so as well. Whether this entails working with students in small discipline-specific groups or one-on-one, the librarian can assess what the students have searched/found/written so far and then intervene accordingly. ${ }^{40}$ To take an upper-division history paper as an example, it may be that the student has struggled to find primary sources, due in large part to not having searched optimal venues. In this case the librarian can assist by pointing to a variety of loci-not just this or that database, but venues such as archives, special collections, or eminently rich online sites such as the Census Bureau or Google Magazines. The librarian can capitalize on the teachable moment 
by emphasizing the fact that today's secondary sources - such as newspapers - in some cases become yesterday's primary sources. More subtly, in a significant move that unites intertextuality, history, and search terms, the librarian can accentuate the point that the student may need to search the topic under various terms according to the era(s) under exploration. As an obvious example, one might have to variantly search the terms "negro," "black," and "African American." Such engagement with something seemingly as simple as keyword search terms can begin to make real for students how attitudes and norms inhere in sources. A recognition that things have not always been called what we currently call them can not only expand student ability to imagine other times or cultures but can also help them think outside their personal framework to find further sources on their own by using such handles from those terms and cultures. At this level, the heightened sensitivity to linguistic cues embedded in the sources discovered through research can inform the content of the writing. When the stars are in alignment, the librarian in such sessions with upper-division students helps them generate enthusiasm both for the process of research related to the paper and for potentials that might be realized in the paper.

The arguments presented here have another important implication for instruction, although it is perhaps less obvious. This pertains to current student search practices and the potential for rapid development of expertise. From the foregoing, we have seen that students already have fundamental searching experience, no matter how rudimentary. They already make choices by clicking on particular items in a given result list. Such a foundation, no matter how naively used, gives them a platform from which they can gain significant database expertise with relatively limited practice. What undergraduates need to underpin effective practice are some essential strategies.
First of all, rather than arm them with an otiose arsenal of retrieval tools, it is much more to the point to help them solve the problem of choosing which tools will "prove helpful in a given situation." ${ }^{41}$ It is necessary to get them inside the databases and to work with the features offered within the structure, such as thesauri, indexes, and full-text linking. It is also necessary to share strategies for guessing which results might be best for a given purpose (strategies, for instance, based on clues embedded in citations, abstracts, and journal titles). The less obvious implication for instruction, then, is this: undergraduate students, already familiar with search practice, when provided with adequate conceptual foregrounding and sufficient practice with academic research tools, can easily be placed in a position to counsel and coach their peers both as reference providers and as providers of information literacy instruction. Twenty years ago it would have been deemed an unreasonable and fiscally unsound leap to train students to conduct pay-for-time DIALOG searches, but the threshold for basic database expertise is far lower than it used to be, and the skill level necessary to support undergraduate research does not require the training associated with an advanced degree. Such basic training and deployment of students is currently taking place at more than one institution. ${ }^{42}$ Certainly, from a social stand point, students are already better equipped than librarians to connect with student learners, and training them as peer coaches and counselors not only provides them with a higher level of expertise personally but becomes a means of communicating that expertise among their peers.

It may be objected that I have placed undue emphasis on database searching in both this paper and in all the preceding implications for instruction. I would like to stress that such searching is not here presented as an end in itself, but rather for its important ramifications beyond the collegiate domain. It is viewed here in its enduring importance as a means 
toward increasing lifelong intertextual skills. The varieties of content available through database subscriptions, and the tools for its discovery, are of course among the richest resources that academic libraries have to offer, and students can benefit from using databases for coursework. ${ }^{43}$ However, after graduation, most students will no longer have access to these costly resources. As their position in the information landscape reverts to noncollegiate status, and as the information landscape itself continues to change, what will remain important will not be their ability to find a peer-reviewed journal in a database but their skills in interpreting how pieces of information relate to each other, rapidly integrating and vetting source information, and navigating between such "pieces of information." In the current and evolving information environment, a key component of intertextual skill will be the ability to become adept, even economical, in the art of searching, navigating, and massively winnowing results. Practice in database searching can nurture such expertise.

\section{Conclusion and Suggested Directions for Research}

Searching, as shown by Rouet, requires complex intertextual skills that unfold in a set of cycles and should not be relegated to the class of lower-order thinking. The scanning, sorting, and selecting involved in search are not isolated processes but unfold in a textual continuum. As with all effective reading, this requires goals, strategies, and coherence. ${ }^{44}$

In looking at the role of search in the context of the undergraduate paper, I have argued that students should be rapidly introduced to the practice of database searching, not only to the end of finding quality sources for their research papers but also to experience the important role of search within the research-writing process. I have also argued that student engagement with databases increases intertextual skills. These intertextual skills, in turn, foster the development of critical thinking skills, a legacy that will persist after graduation.

One of the advantages of the brief conceptual overview and trial-by-fire approach to instruction that I have proposed based on these reflections is that it abrogates the dichotomy sometimes drawn between "the traditional bibliographic paradigm, centering on the location of sources" and a process approach that emphasizes "interpreting, formulating, and learning in the process of information seeking." 45 The instructional approach suggested here does not draw a line between "sources" on one side and "process" on the other; instead, it acknowledges the dynamic interaction of sources and process. I do not, in fact, see how the two can be separated in practice: just as one does not play soccer without a ball, searching involves the searching of something.

I have also argued that current student practice in Internet searching primes students of the present era for rapid entry into the academic database environment. Vivid conceptual frameworks and active engagement with databases immediately helps students advance their search and information skills. I have even proposed that undergraduates, with sufficient guidance and tutelage, can serve as able peer reference-providers and instructional providers to other undergraduates.

Evidence for the immediate usefulness of the instructional practices I have proposed should be amenable to the forms of assessment typically administered to gauge the efficacy of information literacy instruction. To establish clear evidence for my claim that database searching increases intertextual skills, some relatively straightforward assessments could also be designed and executed. These would require pretests and posttests and could entail a scenario-based survey eliciting responses as to the relationships of "information pieces" about several texts. Assessment of the effect of database searching on critical thinking would require control groups and the participation of 
the writing faculty in applying a rubric to the written products. Assessment of these papers could connect verified practice in database searching with intertextual skills as evidenced by source information and gains in critical thinking as evidenced by better ranging of argument.

A broader assertion I have made, however, will not be so easy to support. Although I have boldly claimed that critical thinking skills are transferable to postcollegiate contexts, there is scant evidence to warrant this claim. Nonetheless, I stand by it; and I am, moreover, fully willing to expend my instructional energies on the basis of it. The entwined agendas of information literacy, lifelong learning, and critical thinking have long been based on such "articles of faith" and, in fact, remain vulnerable to critique on precisely this count. ${ }^{46}$ Therefore, valuable and meaningful longitudinal research to support the claims of gains in critical thinking and its transferability are begging to be undertaken. Such research will necessarily be ambitious, requiring not only evaluation of written products as artifacts of learning but incorporating the analysis of student research logs and interviews at multiple points throughout the student career of the research subjects. Moreover, to demonstrate transferability, such research will require establishing postcollegiate contact with a sufficient number of subjects to generate meaningful follow-up data. Such a multiyear project will require ample time and funding; but, if we are to act and design instruction on the basis of knowledge rather than faith, it will prove well worth the effort.

\section{Use these Archive-Quality Scanners to}

Create digital archives $\cdot$ Print books on demand $\cdot$ Create course curriculum materials - Create 3-D digital collections for the Web \& 3rd party content managers

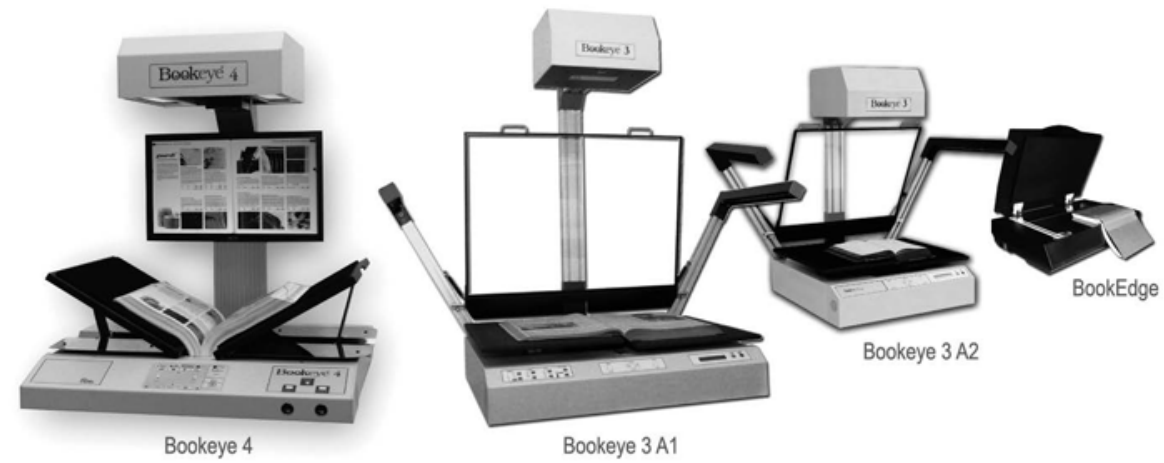

Opus runs the best archive/preservation-quality scanners available today and manages projects ranging from scanning a few pages to creating complete digital libraries using sophisticated, multi-stage workflow systems.

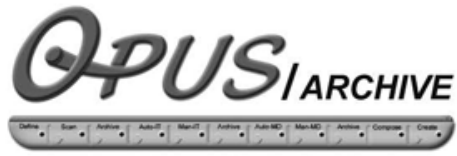

Digital archiving without the complexity

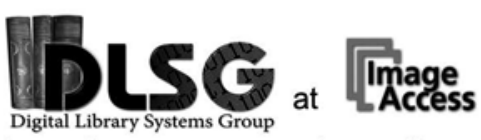

800.378.5432 | www.imageaccess.com | www.dlsg.net 


\section{Notes}

1. David Barton, Literacy: An Introduction to the Ecology of Written Language, 2nd ed. (Malden, Mass.: Blackwell, 2007), 36.

2. Ibid., 35 .

3. Richard Arum and Josipa Roksa, Academically Adrift (Chicago: University of Chicago Press, 2011). In presenting results of a nationwide study organized by the Social Science Research Council (SSRC), Arum and Roksa see a significant correlation between improved student learning in critical thinking at the collegiate level only when students have demanding faculty who require "that students both read more than forty pages a week and write more than twenty pages over the course of a semester," 93.

4. See Annemaree Lloyd, "Framing Information Literacy As Information Practice: Site Ontology and Practice Theory," Journal of Documentation 66, no. 2 (2010): 245-57; Gloria J. Leckie, "Desperately Seeking Citations: Uncovering Faculty Assumptions about the Undergraduate Research Process," The Journal of Academic Librarianship 22, no. 3 (1996): 201-08; John Seely Brown, Allan Collins, and Paul Duguid, "Situated Cognition and the Culture of Learning," Educational Researcher 18, no. 1: 32-42.

5. Alison J. Head and Michael B. Eisenberg, "Project Information Literacy Progress Report: Truth Be Told: How College Students Use and Evaluate Information in the Digital Age," (Seattle, Wash.: The Information School, University of Washington, 2010), 10, available online at http:// projectinfolit.org/pdfs/PIL_Fall2010_Survey_FullReport1.pdf [accessed 20 June 2011].

6. Leckie, "Desperately Seeking Citations," 202.

7. Head and Eisenberg, "Project Information Literacy Progress Report," 20.

8. Miriam J. Metzger and Andrew J. Flanagin, Digital Media, Youth, and Credibility (Cambridge, Mass.: MIT Press, 2008), 42; Head and Eisenberg, "Project Information Literacy Progress Report," 21.

9. Head and Eisenberg, "Project Information Literacy Progress Report," 33.

10. Ibid., 33.

11. Ibid., 33.

12. Sheril Hook, "Teaching Librarians and Writing Center Professionals in Collaboration: Complementary Practices," in Centers for Learning: Writing Centers and Libraries in Collaboration, ed. James K. Elmborg and Sheril Hook (Chicago: Association of College and Research Libraries, 2005), 21.

13. Barbara Fister, "The Research Processes of Undergraduate Students," The Journal of Academic Librarianship 18, no. 3: 167; James K. Elmborg, "Libraries and Writing Centers in Collaboration: A Basis in Theory," in Centers for Learning: Writing Centers and Libraries in Collaboration, ed. James K. Elmborg and Sheril Hook (Chicago: Association of College and Research Libraries, 2005), 9.

14. Christine Bruce, The Seven Faces of Information Literacy (Adelaide, Australia: Auslib Press, 1997), 38.

15. Sirje Virku, "Information Literacy in Europe: A Literature Review," Information Research 8 , no. 4 (2003): 23, available online at http://informationr.net/ir/8-4/paper159.html [accessed 3 March 2011].

16. Association of College and Research Libraries, "Information Literacy Competency Standards for Higher Education" (2000), available online at www.ala.org/ala/mgrps/divs/acrl/ standards/ informationliteracycompetency.cfm [accessed 3 March 2011].

17. Marcia Bates, "The Design of Browsing and Berrypicking Techniques for the Online Search Interface" (1989), available online at http://gseis.ucla.edu/faculty/bates/berrypicking.html [accessed 3 March 2011]; Bruce, The Seven Faces of Information Literacy, 7.

18. Head and Eisenberg, "Project Information Literacy Progress Report," 18.

19. Developing the skills of critical thinking has been, and continues to be, one of the "articles of faith" of higher education. In Academically Adrift, Arum and Roksa cite statements by the American Association of University Professors, multiple university administrators, and survey results, including the finding that " 99 percent of college faculty say that developing students' ability to think critically is a 'very important' or 'essential' goal of undergraduate education," 35. See also Jaroslav Pelikan, The Idea of the University: A Reexamination (New Haven: Yale University Press, 1992), 6-7.

20. William Condon and Diane Kelley-Riley, "Assessing and Teaching What We Value: The Relationship between College-Level Writing and Critical Thinking Abilities," Assessing Writing 9 (2004): 56-75. Condon and Kelly-Riley challenge the widely and long-held assumption that practice in writing necessarily fosters the development of critical thinking, 57-58.

21. Head and Eisenberg, "Project Information Literacy Progress Report," 37, footnote 44. See also the "Information Literacy Competency Standards for Higher Education," available online 
at www.ala.org/ala/mgrps/divs/acrl/standards/informationliteracycompetency.cfm [accessed 3 March 2011].

22. Jean-Francois Rouet, The Skills of Document Use: From Text Comprehension to Web-Based Learning (Mahwah, N. J.: Lawrence Erlbaum Associates, 2006), 11.

23. Ibid., 111.

24. Ibid., 93.

25. Ibid., 93.

26. Ibid., 189.

27. Ibid., xvii.

28. Ibid., 189.

29. Malcom Beckwith Parkes, "The Influence of the Concepts of Ordinatio and Compilatio on the Development of the Book," in Medieval Learning and Literature, ed. J.J.G. Alexander and M. Gibson (Oxford: Clarendon Press, 1976), 135.

30. Rouet, The Skills of Document Use, 189.

31. Ibid., 67.

32. Lynn Silipigni Connaway, "The Researcher of the Future," OCLC Research, Annual Research Libraries Group Partnership Meeting, 2010, slide 5, available online at www.oclc.org/ research/events/20100609c.pptx [accessed 20 June 2011].

33. Heting Chu, Information Representation and Retrieval in the Digital Age (Medford, N. J.: Information Today, 2007), 85. Chu refers to the progressive whittling down of a search from the broadest start "the successive fraction approach," but it is colloquially known as the funnel technique.

34. Connaway, “The Researcher of the Future," slide 6; Eric Novotny, "I Don't Think I Click: A Protocol Analysis Study of Use of a Library Online Catalog in the Internet Age," College \& Research Libraries 65, no. 6 (2004): 531.

35. Rouet, The Skills of Document Use, 191.

36. For "counselor," see Carol Kuhlthau, Seeking Meaning: A Process Approach to Library and Information Services 2nd ed. (Westport, Conn.: Libraries Unlimited, 2004), 107-44; for "coach," see Maria-Carme Torras and Tove Pemmer Saetre, Information Literacy Education: A Process Approach, Professionalizing the Pedagogical Role of Academic Libraries (Oxford: Chandos Publishing, 2009), 83.

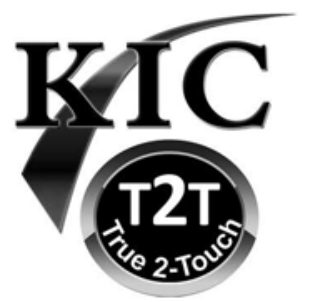

\section{Knowledge Imaging Centers}

\section{Self-Serve Systems to Mine Your Print Collections}

Students entering college expect digital. Most of your scholarly assets are in print form. That's why speed and throughput are so important when choosing self-serve digitizing systems. And that's why KIC is available to half of the students at the top 100 academic institutions.

\section{Multiple Unit Purchases Start at \$ 3,999}

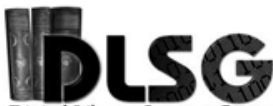
at

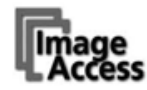

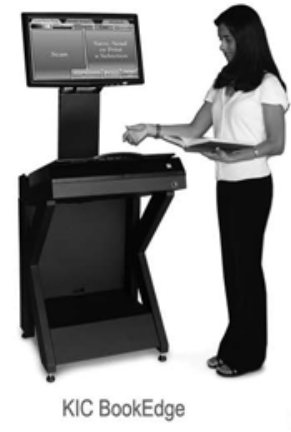

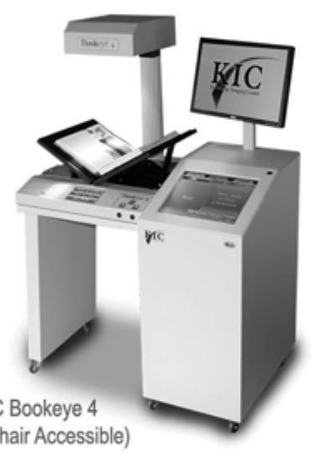


37. Marilyn Deegan and Kathryn Sutherland, Transferred Illusions: Digital Technology and the Forms of Print, (Surrey, United Kingdom: Ashgate Publishing Limited, 2008), 27-28.

38. Jesse Vestermark, Librarian for the College of Architecture and Engineering Design, invented this exercise and first used it during the Summer Institute 2010, a three-week course offered to first-generation college students at California Polytechnic State University, San Luis Obispo.

39. Peter W. Foltz, "Comprehension, Coherence, and Strategies in Hypertext and Linear Text," in Hypertext and Cognition, ed. Jean-Francois Rouet, Jarmo J. Levonen, Andrew Dillon, and Rand J. Spiro (Mahwah, N.J.: Lawrence Erlbaum Associates, 1996), 128.

40. Torras and Saetre devote chapter 4 of Information Literacy Education to the librarian's role in supporting the research-writing process of graduate students and propose positioning the librarian in a cosupervisory role, with the faculty taking the role as primary supervisor and the librarian as secondary supervisor (76). Because of the greater intensity of graduate work, many, but not all, of their suggestions can be translated to the undergraduate milieu.

41. Eric Espéret, "Notes on Hypertext, Cognition and Language," in Hypertext and Cognition, ed. Jean-Francois Rouet, Jarmo J. Levonen, Andrew Dillon, and Rand J. Spiro (Mahwah, N.J.: Lawrence Erlbaum Associates, 1996), 152.

42. At the California Polytechnic State University, the author has participated in such an initiative with the LibRAT Program. LibRATs (Library Reference Assistance Technicians) provide desk and chat reference and deliver instructional sessions to lower-division courses in support of research papers/assignments. The online evaluations of satisfaction with their instruction are on a par with the evaluations of the librarians who provide such sessions, and 320/356 of the students in attendance (90\%) agreed that all students on campus should attend such sessions. Brigham Young University is also harnessing students to provide library instruction: Suzanne Julian, The Power of Peer Mentors in Library Instruction, ACRL Conference 2011, Poster Presentation March 21. For earlier instances of library peer tutor and peer assistance programs, see Susan Deese-Roberts and Kathleen Keating, Library Instruction: A Peer Tutoring Model (Englewood, Colo.: Libraries Unlimited, 2000), 21-31.

43. Head and Eisenberg note a "gap between the plethora of Web sources and the incredibly rich information sources libraries make available to students and the sources that students actually use (35)." Sadly, 42 percent of the respondents in the Head and Eisenberg study found library databases to be "the most difficult parts of searching," and Connaway, in "The Researcher of the Future," also reported that users encountered "database interface difficulties" (slide 9). On the other hand, Connaway noted that users, once they were taught how to use databases, always used them and found them "familiar and convenient" (slide 11). This finding should serve as an encouragement to engaging students with databases as early as possible in their collegiate careers.

44. Foltz, "Comprehension, Coherence, and Strategies in Hypertext and Linear Text," 126.

45. Carol Kuhlthau, Seeking Meaning: A Process Approach to Library and Information Services, 2nd ed. (Westport, Conn.: Libraries Unlimited 2004), 189. See also, Torras and Saetre, Information Literacy Education, 83-94.

46. For the tradition of linking of library-related instruction to the development of critical thinking skills, see Erin L. Ellis and Kara M. Whatley, "The Evolution of Critical Thinking Skills in Library Instruction, 1986-2006: A Selected and Annotated Bibliography and Review of Selected Programs," College and Undergraduate Libraries 15, no. 1/2: 5-21. For challenges to the assumptions about the impact of information literacy on critical thinking, see Condon and Kelley-Riley (supra, note 20). For a challenge to the assumption that information literacy skills taught in instruction sessions transfer to lifelong learning skills, see Peter Williams, "Against Information Literacy," Library + Information Update 5, no. 7/8 (2006): 20. For a critique of information literacy as a phenomenon that impedes true critical thinking and perpetuates the hegemonic status quo, see Christine Pawley, "Information Literacy: A Contradictory Coupling," Library Quarterly 73, no. 4 (2003): 422-52. For a conclusion about the pragmatic role librarians should play that is quite similar to the one presented in this article (sans emphasis on the importance of searching proper or on peer-provided instruction), see Stanley Wilder, "Information Literacy Makes All the Wrong Assumptions," Chronicle of Higher Education 51, no. 18 (Jan. 7, 2005): B1; Wilder concludes: "Students are apprentices in the reading and writing of their chosen disciplines, and librarians are experts who can help them master those tasks. Here is an educational function that creates real value within our institutions." 